\title{
Analogy of Isophthalic Polyester Based Bamboo Fabric Mat and E-glass Reinforced Composite
}

\author{
A.K. Arun Raja, K. Arun Vasantha Geethan' P. Sabarish Kumar, A. Shagul Hameed, S.Vivekanandan
}

\begin{abstract}
Bamboo (Bambusoideae) normally found abundant in South Asian region is known to have a better fabric property which is now researched as a natural alternative in various applications and field. Various research are being carried out to find a suitable replacement for the non-bio degradable plastic reinforced composites, which has a negative impact on the Environment. A similar attempt is made to present an overview of recent research efforts addressing the properties of isophthalic polyester based Bamboo fabric mat as a replacement for E-glass fabric. The Bamboo fabric is made water repellent and the properties are promoted through mercerization process. The mercerization process is done using $8 \%$ of sodium in water to form the sodium hydroxide (NaOH). The property of the fabric is further promoted by adding charcoal, during the hand moulding process. The composite material is developed with the help of isophthalic polyester resin with $2 \%$ of accelerator and hardener used along with it. Experiments are carried out as per ASTM standards to find the mechanical properties namely, tensile strength and modulus, flexural strength and modulus, and impact strength. In addition to mechanical properties, water absorption capacity and the rate of burning of the composites is also studied. Further, fractured surface of the specimen is subjected to morphological study using scanning electron microscope. With help of the research and study, it can be found whether the isophthalic resin-based bamboo fabric mat can be used as an alternate for E-Glass fabric composite in various applications such as automobile and structural applications.
\end{abstract}

Keywords: Bambusoideae, E-Glass, Isophthalic, Mercerization, Reinforcement.

\section{INTRODUCTION}

In the modern era, the demand for natural composite is increasing every day. In a research conducted in Japan in 2001, it is the total amount of consumption of Glass Fibre Reinforced Plastics was about 382 thousand tons in their country. The replacement of the natural polymer over synthetic polymer is achievable due to the advantage which natural polymer possess.

Revised Manuscript Received on September 15, 2020.

* Correspondence Author

Mr. A. K. Arun Raja*, Assistant Professor in Mechanical Engineering Department in St. Joseph's Institute of Technology, OMR, Chennai, Tamil Nadu, India.

Dr. K. Arun Vasantha Geethan Professor and Head Of the Department of Mechanical Engineering St. Joseph's Institute of Technology, OMR, Chennai, Chennai, Tamil Nadu, India.

Mr. P Sabarish Kumar Assistant Professor in Mechanical Engineering Department in St. Joseph's Institute of Technology, OMR, Chennai

Mr. A Shagul Hameed B. E. degree in mechanical engineering in St. Joseph's Institute of Technology, OMR, Chennai, Tamil Nadu, India.

Mr. S. Vivekanandan is a final year student pursuing his B. E. degree in mechanical engineering in St. Joseph's Institute of Technology, OMR, Chennai, Tamil Nadu, India.

(C) The Authors. Published by Blue Eyes Intelligence Engineering and Sciences Publication (BEIESP). This is an open access article under the CC BY-NC-ND license (http://creativecommons.org/licenses/by-nc-nd/4.0/)
Eco-friendly green composites from crop-derived plastics and plant derived fibre are novel materials for the 21st century and can be of great importance to the world of engineering materials and science[1]. The major advantages of natural composites are low cost, low density, easily accessible and renewable. The major concern regarding natural polymer is its mechanical strength not up to the synthetic polymer. But this disadvantage can be overcome, by adding fillers and fibres. With this, most of the non-renewable synthetic polymer can be replaced with the renewable natural polymer. The Bamboo is the fast-growing plant in the world. It grows 21 centimetre per day and reaches its final height in just 6 months. The maturity of the Bamboo is 4-6 years. Bamboo are naturally growing plant where enormous capacity of the plant is renovated without reseeding. Environmental benefits of planting Bamboo plants are preventing soil erosion, increases the organic material of the soil. The Bamboo plant also observes large amount $\mathrm{CO}_{2}$ from atmosphere compared to other many plants. Researchers say that 1 hectare of Bamboo plants will sequesters 62 ton of $\mathrm{CO}_{2}$ per year[2]. Due to the longitudinally aligned fibre body, it derives the high strength to weight ratio, which is why the Bamboo fibres are often termed as 'natural glass fibre'[3]. Bamboo fibres can be extracted using various methods like steam explosion, chemical extraction, mechanical extraction and combination of both chemical and mechanical extraction. Apart from the environmental aspects, various reasons are also put forth for the selection of Bamboo fabrics. The fibre yield of Bamboo per hectare is comparatively higher than many plants with lower number of days for growing cycle. Also, the Bamboo fabric shows a lot of similarities when compared with E-Glass fibre, which includes the same elastic behaviour under tensile load. In order to enrich the hydrophobicity of the natural fibre, chemical treatment with appropriate coupling agent, will enhance the overall mechanical property and the environmental performance [4].

\section{FABRICATION}

\section{A. Materials used}

The Bamboo fabric is ordered and purchased from the Anakaputhur Jute Weavers Association. The E-glass mat and the isophthalic polyester resin, and corresponding hardener and accelerator supplied by Sakthi fibre glass, which were used to prepare the composites. The Bamboo fabric and E-Glass are bow obtained in mat form.

\section{Published By:}

Blue Eyes Intelligence Engineering and Sciences Publication

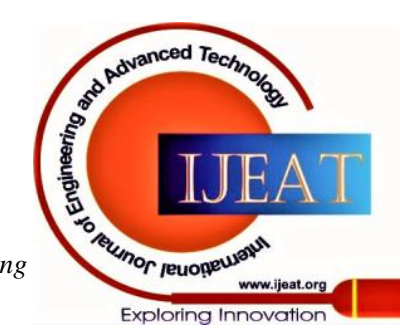




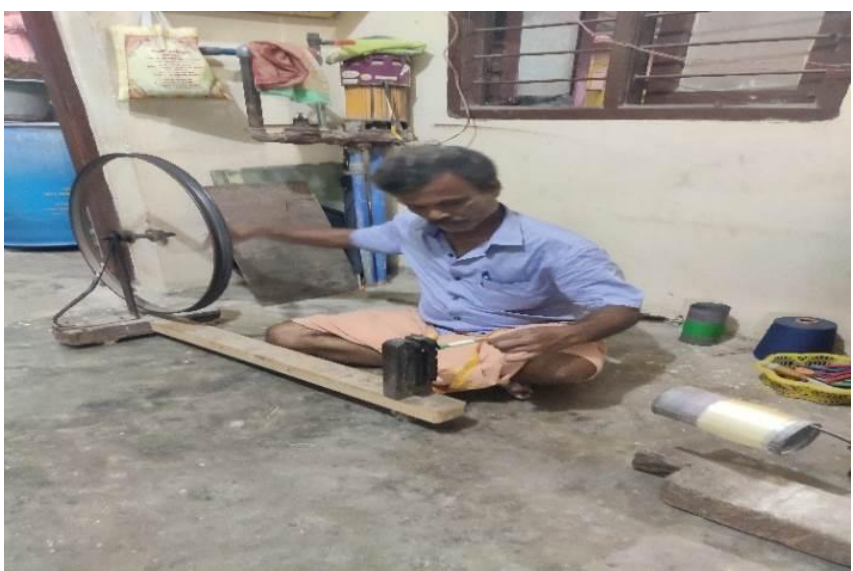

Fig. 1. Weaving of Bamboo Fabric

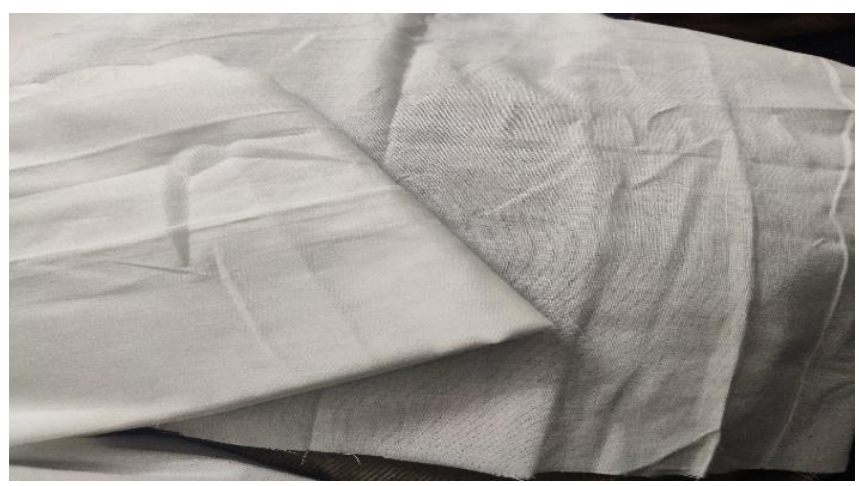

Fig. 2. Bamboo Fabric

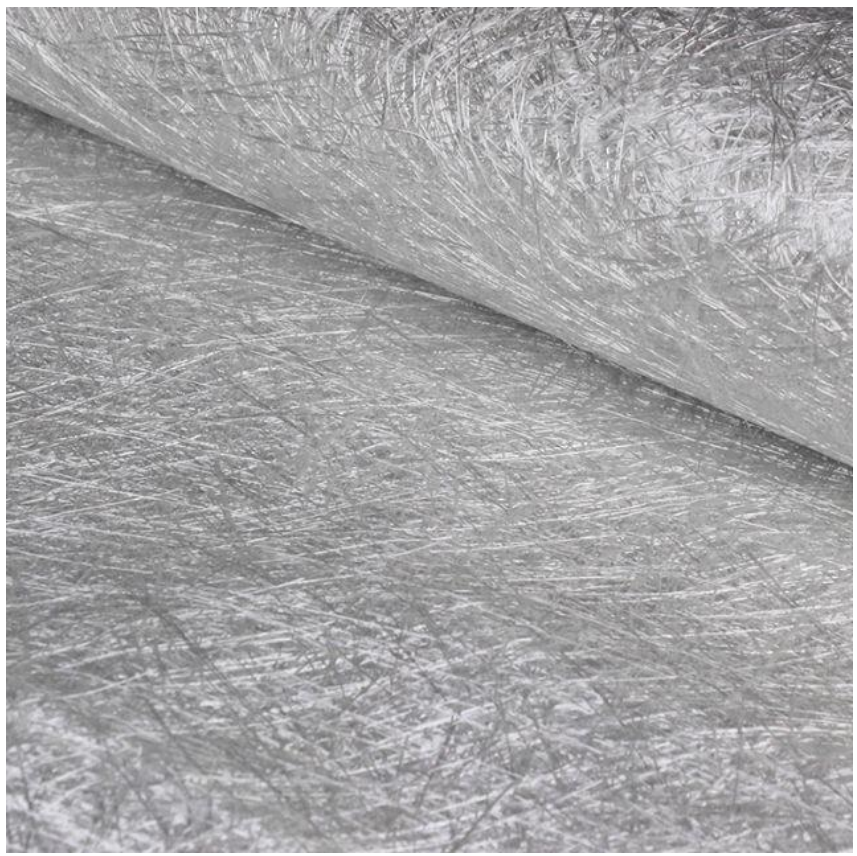

Fig. 3.E-Glass Fabric

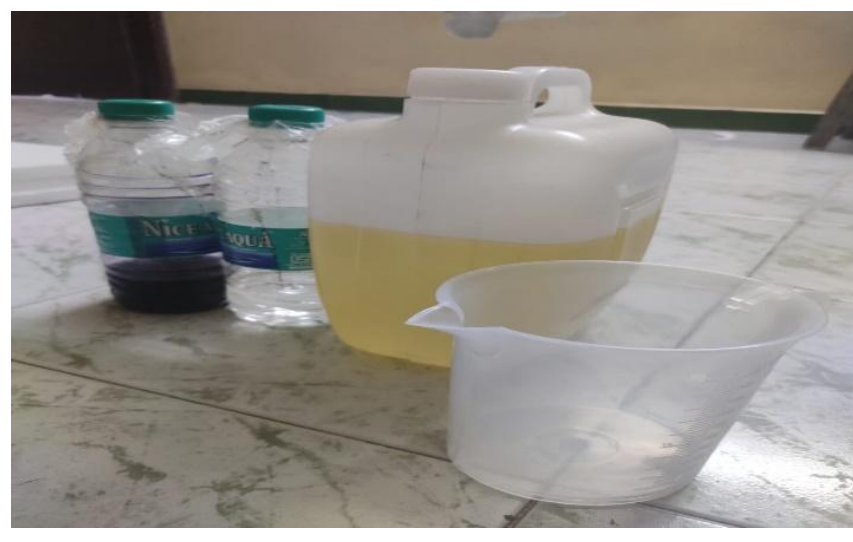

Fig. 4. Isophthalic resin, hardener and Accelerator

The fabrics are isolated and dried separately. In order to increase the properties of the Bamboo fabrics, it is chemically treated with water solution containing $8 \%$ sodium salts dissolved in it, this process is called as mercerization process.

Fibre $-\mathrm{OH}+\mathrm{NaOH} \rightarrow$ Fibre $-\mathrm{O}-\mathrm{Na}+\mathrm{H}_{2} \mathrm{O}$ [5] (1) The Bamboo fabric is immersed in the $1 \mathrm{~N} 8 \% \mathrm{NaOH}$ solution for 8 hours followed by drying it in closed room atmosphere for 48 hours. This process converts the hydrophilic property of the Bamboo fabric into hydrophobic property, thus making it a water negating specimen. Then the Bamboo fabrics where cut into uniform shape.

\section{B. Composite Fabrication}

The isophthalic resin and its corresponding accelerator and hardener were mixed in the ratio 1:0.02, respectively. Then, the pure charcoal brick is crushed into fine particles and is added up to $10 \%$ of the volume of the isophthalic resin solution. In order to enhance improved internal bonding and to increase crosslink density of the composites, the charcoal is used as the filler material to the isophthalic resin solution[6].

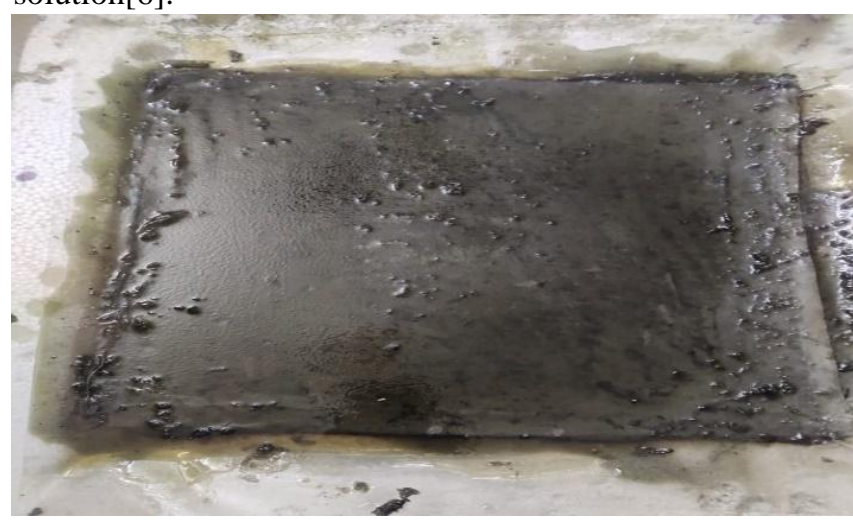

Fig. 5.Bamboo Fabric Composite

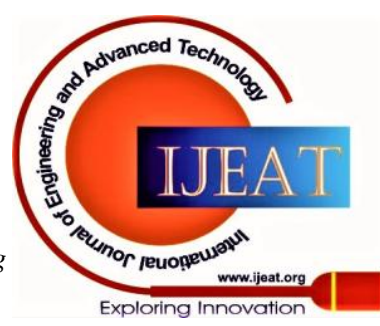




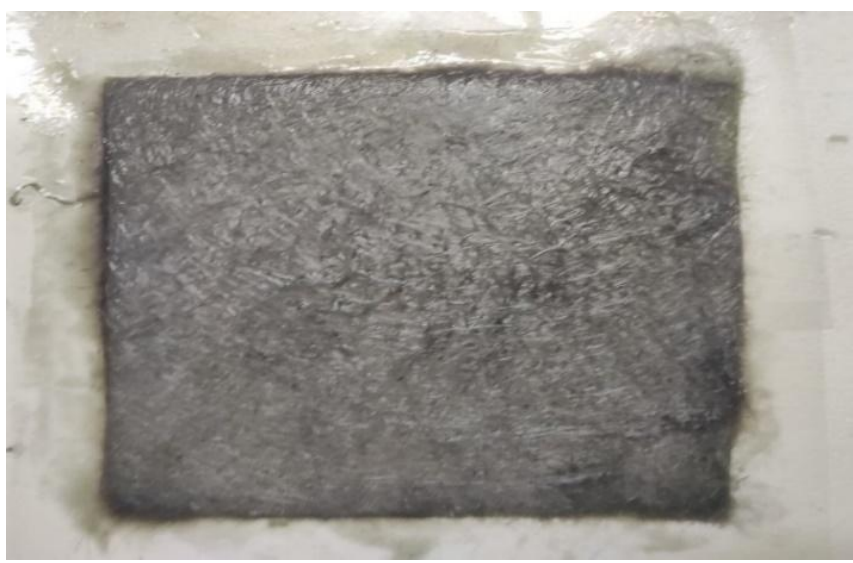

Fig. 6.E-Glass Fibre Composite

Initially $750 \mathrm{ml}$ of isophthalic resin is taken in a container, then the respective quantity of hardener and accelerator are added along with the resin mixture. The composite is obtained by stratifying the fabrics and isophthalic resin mixture stacked alternatively. The process is carried out by hand moulding process and the outcome of the composite is shown in the Fig.5 and Fig.6.

\section{METHODOLGY}

Various mechanical test is carried out in order to understand and compare the mechanical property of the isophthalic based Bamboo fabric and E-glass fabric. All the mechanical test is carried out according to the ASTM D standards. The following are mechanical test carried out:

\section{A. Tensile Test}

A tensile test, also known as a tension test, is one of the most fundamental and common types of mechanical testing. In tensile test, a tensile (pulling) force is applied on a material and the reading are measured based on the specimen's response to the stress. With help of Tensile test, the strength of the material tested can be determined and the test is carried out to determine the breaking point of the material tested. The tensile strength and modulus were determined from the stress-strain curves. Researchers says, when compared with other natural fibers, Bamboo has Higher elongation at Fracture i.e. more flexible than Jute and Kenaf[7]. Five samples were tested in each set and average is tabulated for each specimen.

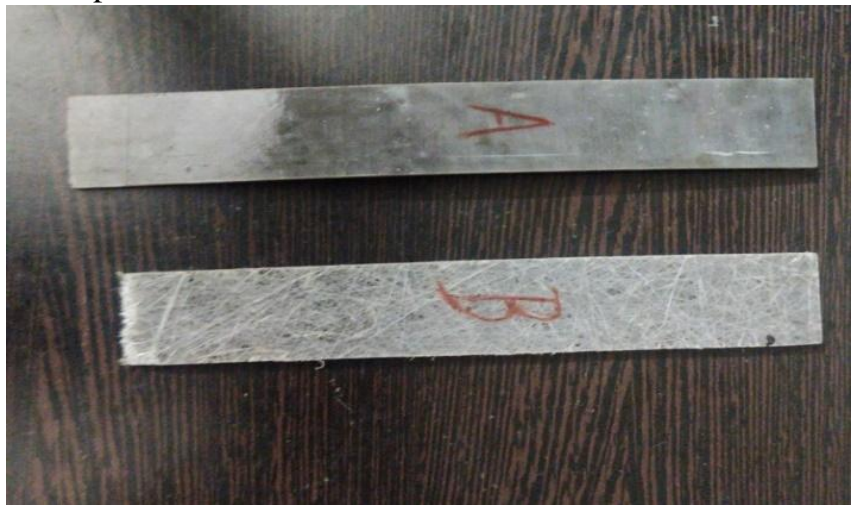

Fig. 7. Test specimen made for Tensile Test

Fig.7 shows the specimens prepared for tensile test. Fig.8 represents the anatomy of the Universal Testing Machine (UTM). Tensile tests are typically conducted on electromechanical or Universal Testing Machine (UTM) at a crosshead speed of $50 \mathrm{~mm} / \mathrm{min}$ and a gauge length of 50 $\mathrm{mm}$. The Tensile test was conducted according to the ASTM D 638 standards. The test specimens used were rectangular in shape with dimensions $120 \mathrm{~mm}$ x $12.5 \mathrm{~mm}$ x $3 \mathrm{~mm}$. Five samples were tested in each set and the average is tabulated for each specimen for further calculation.

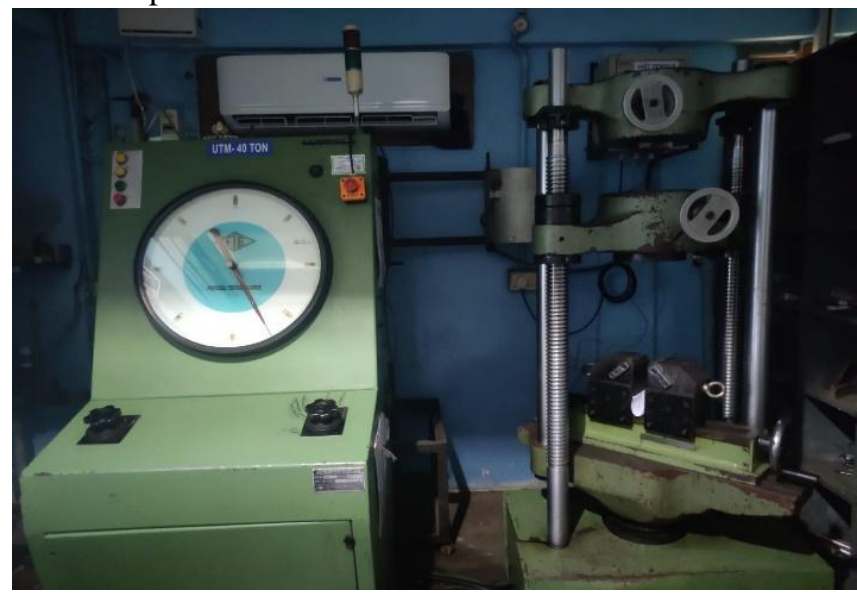

Fig. 8. Universal Testing Machine (UTM)

\section{B. Flexural Test}

Flexure tests are generally used to determine the flexural modulus or flexural strength of a material. Flexural strength is defined as a materials ability to resist deformation under load. The material is laid horizontally over two points of contact (lower support span) and then a force is applied to the top of the material through either one or two points of contact (upper loading span) until the sample fails. The maximum recorded force is the flexural strength of that sample. The flexural modulus of the material increases with increase in fiber loading[8].

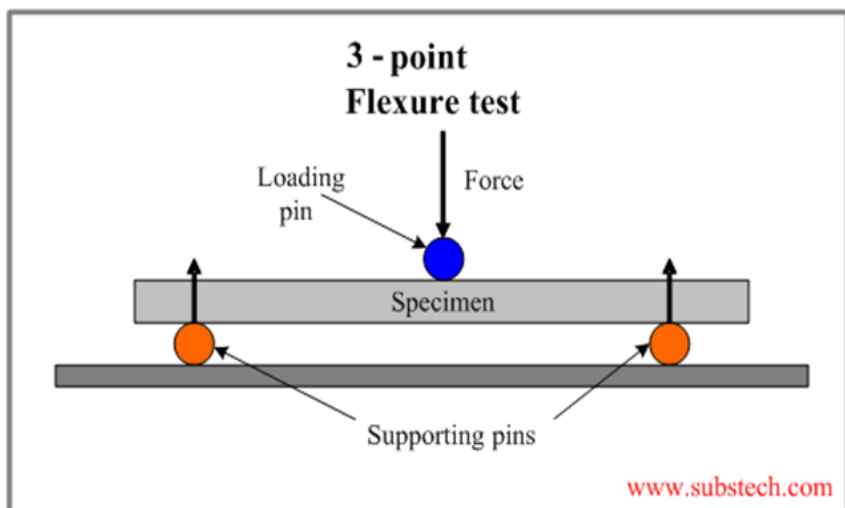

Fig. 9. Pictorial Representation of 3-point Flexural Testing

Flexural test which generally promotes failure by inter-laminar shear. A three-point bend test consists of the sample placed horizontally upon two points and the force applied to the top of the sample through a single point so that the sample is bent in the shape of a "V. This test is conducted as per ASTM D790 standard using UTM.

\section{Published By:}

Blue Eyes Intelligence Engineering

and Sciences Publication

(C) Copyright: All rights reserved.

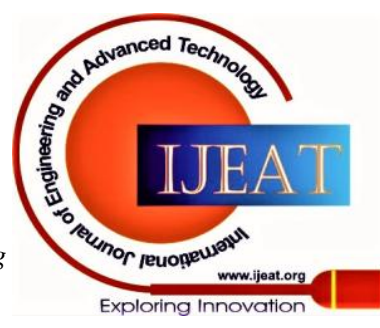


Flexural properties of the composites were measured by a three-point loading system as per ASTM D 790 using a universal testing machine with rectangular samples of dimension $120 \mathrm{~mm}$ x $12.5 \mathrm{~mm}$ x $3 \mathrm{~mm}$. A minimum of five samples were tested in each case and average of these results are tabulated for future calculation. Flexural test arrangement is shown in the Fig.9. The maximum fiber stress at failure on the tension side of a flexural specimen is considered the flexural strength of the material.

\section{Compression Test}

The goal of a compression test is to determine the behavioral response of the material while it is subjected to a compressive load by measuring fundamental variables, such as, strain, stress, and deformation. A compression test is a test in which a material experiences opposing forces that push inward upon the specimen from opposite sides. By testing a material in compression, the compressive strength, yield strength, ultimate strength, elastic limit, and the elastic modulus among other parameters is determined. Both the samples are taken as the measurement of $120 \mathrm{~mm} \times 12.5 \mathrm{~mm} \times 3 \mathrm{~mm}$ thickness. The compression test is also carried out in the universal testing machine. The samples are loaded in the machine and results are tabulated.

\section{Impact Test}

Impact is a single point test that measures a materials resistance to impact from a swinging pendulum. Impact tests are used in studying the toughness of material. A material's toughness is a factor of its ability to absorb energy during plastic deformation. Impact is defined as the kinetic energy needed to initiate fracture and continue the fracture until the specimen is broken. The impact value of a material can also changes with temperature. This test was originally developed for testing metals used for cutting, subsequently used by plastic industries for material toughness[9].

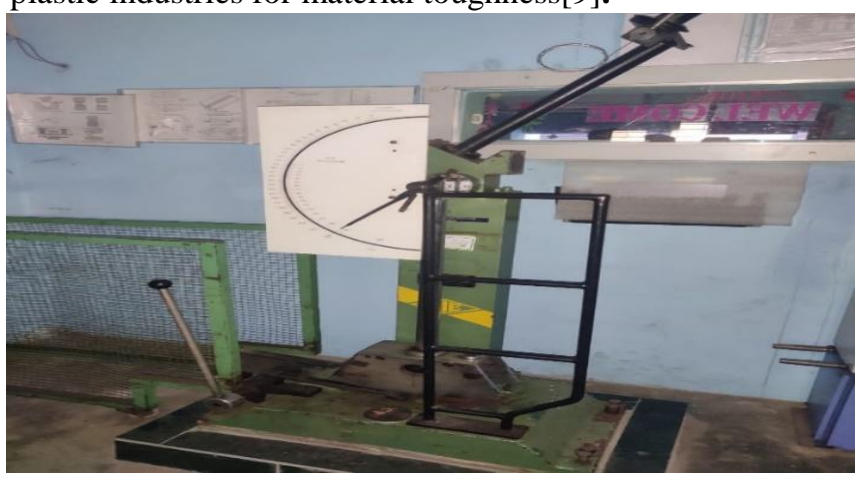

Fig. 10. Impact testing Machine

Generally, at lower temperatures, the impact energy of a material is decreased. The Fig.10 shows the impact testing used for the experimental work. For each case, a sample of 5 is taken and tested and the average value is tabulated.

\section{E. Barcol Hardness}

The Barcol hardness test characterizes the indentation hardness of materials through the depth of penetration of an indentor, loaded on a material sample and compared to the penetration in a reference material. The method is most often used for composite materials such as reinforced thermosetting resins or to determine how much a resin or

Published By:

Blue Eyes Intelligence Engineering

and Sciences Publication

(C) Copyright: All rights reserved.

plastic has cured. The test complements the measurement of glass transition temperature, as an indirect measure of the degree of cure of a composite. It is inexpensive and quick and provides information on the cure throughout a part[10].

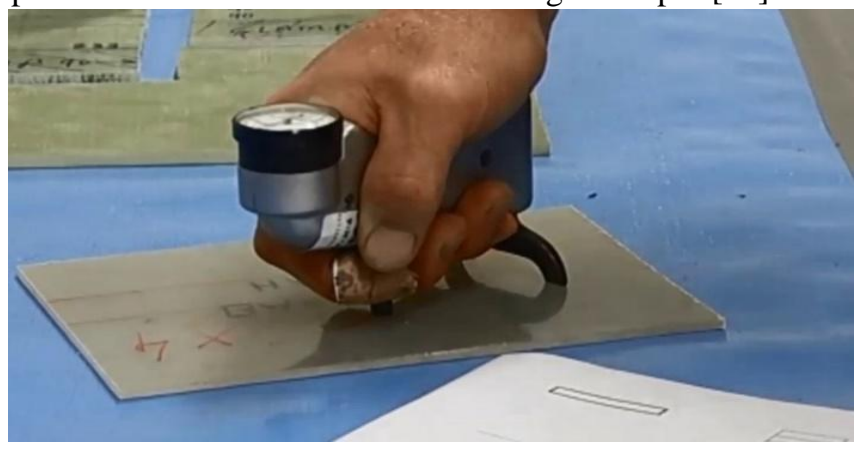

Fig. 11. Barcol Impresser

This is an indentation-type of hardness, where pressure is uniformly applied on the surface of a specimen to the dial indicator maximum reading. The depth of penetration or indentation is then converted into an absolute Barcol number. The Barcol number is automatically generated by the measuring equipment.

\section{F. Water Absorption Test}

Water absorption is used to determine the amount of water absorbed under specified conditions. Factors affecting water absorption include type of plastic, additives used, temperature and length of exposure. The data sheds light on the performance of the materials in water or humid environments.

For the water absorption test, the specimens i.e. E-Glass Fiber and Bamboo Fiber are dried in an oven for a specified time and temperature and then placed in a desiccator to cool. Immediately upon cooling the specimens are weighed. The material is then submerged in water at agreed upon conditions, often $23^{\circ} \mathrm{C}$ for 24 hours or until equilibrium. Specimens are removed, patted dry with a lint free cloth, and weighed to get the rate at which the water is absorbed by that particular specimen.

\section{G. Rate of Burning}

In this test, the result is the measurement of a material's flammability and rate of combustibility of that material. Initially the test specimen is supported horizontally at one end, and the free end is exposed to a gas flame for 30 seconds. After removal of the flame, the test specimen is observed for time and extent of burning. An average burning rate is reported for the composite up to the burnt mark from the ignited end [11].

\section{RESULT AND DISSUCION}

The results are drawn from the average value obtained from the following test mention. Minimum of five samples are used for the testing. The average value is calculated, and the results are tabulated and graphical representation for the results are provided. 
The samples are given the tag $\mathrm{A}$ and $\mathrm{B}$ as mention below A-Bamboo fabric composite

E-Glass fabric composite

Similarly, in graphical representation the Bamboo fabric composite is indicated using blue colour and the E-Glass fabric composite is indicated using orange colour.

\section{A. Mechanical properties}

Considering the Mechanical aspect such as Tensile, Flexural, Compression and Impact Values which is tabulated below in Table-I it could be inferred that E-Glass Fibre has comparatively greater Mechanical properties than Bamboo fabric, but the difference is much negligible.

\section{Table-I:Mechanical properties readings}

\begin{tabular}{|c|c|c|c|c|}
\hline SPECIMEN & $\begin{array}{c}\text { TENSILE } \\
\text { STRENGTH }\end{array}$ & $\begin{array}{c}\text { FLEXURAL } \\
\text { LOAD }\end{array}$ & $\begin{array}{c}\text { COMPRESSION } \\
\text { LOAD }\end{array}$ & $\begin{array}{c}\text { IMPACT } \\
\text { VALUES }\end{array}$ \\
\hline UNITS & $(\mathrm{MPa})$ & $\begin{array}{c}(\mathrm{MPa}) \\
\text { X 10 }\end{array}$ & $\begin{array}{c}\text { (MPa) } \\
\text { X 10 }\end{array}$ & $\begin{array}{c}{ }^{-1} \\
\text { XULES 10 }\end{array}$ \\
\hline A & 47.82 & 24.995 & 45 & 30 \\
\hline B & 59.26 & 29.989 & 63 & 40 \\
\hline
\end{tabular}

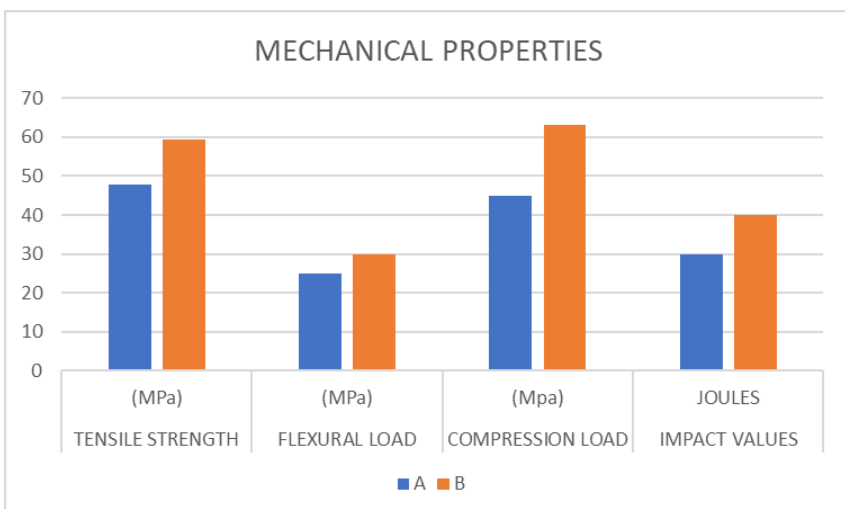

Fig. 12. Comparison of Mechanical Properties.

\section{B. Barcol Hardness}

Based on Barcol Hardness, Bamboo fabric has an average hardness of 28 and E-glass Fibre having 31. This shows that E-glass fibre is comparatively a bit harder than Bamboo fabric.

\section{Table-II:Barcol Hardness readings}

\begin{tabular}{|c|c|c|c|}
\hline \multirow{2}{*}{ SPECIMEN } & \multicolumn{3}{|c|}{ BARCOL HARDNESS } \\
\hline A & 27 & 28 & 26 \\
\hline B & 31 & 33 & 30 \\
\hline
\end{tabular}

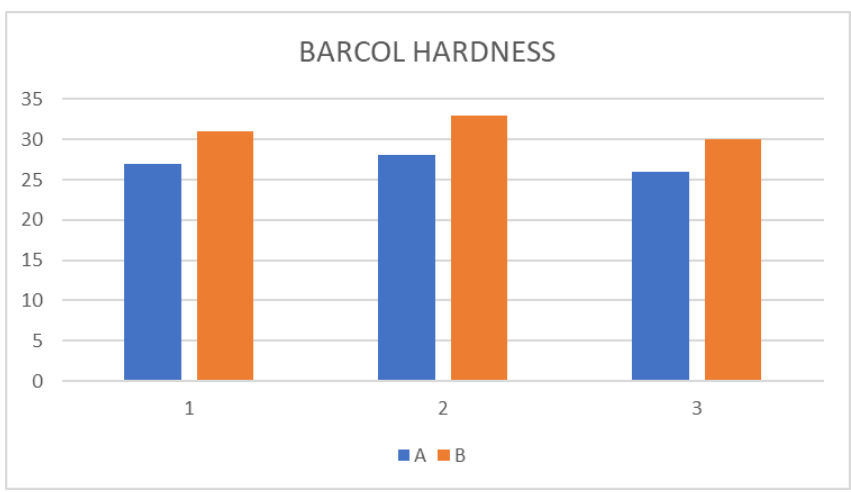

Fig. 13. Comparison of specimens based on Barcol Hardness

\section{Water Absorption Test}

While coming to the water absorption test E-glass fibre has a comparatively less water absorption rate than Bamboo fabric which means that the rate at which the given material absorbs water is high in Bamboo fabric.

\section{Table-III:Water Absorption Test readings}

\begin{tabular}{|c|c|}
\hline SPECIMEN & WATER ABSORPTION TEST \\
\hline UNITS & $(\%)$ \\
\hline A & 0.09 \\
\hline B & 0.07 \\
\hline
\end{tabular}

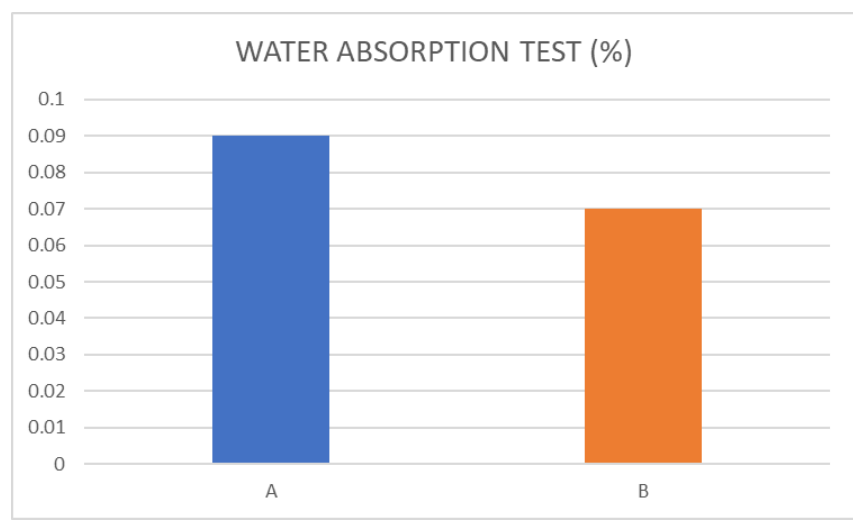

Fig. 14. Comparison of specimens based on water Absorption.

\section{Rate of Burning}

In terms of Rate of burning it is high in Bamboo fabric followed by E-glass by small margin which affects the application and usage of the material.

Table-IV:Rate of Burning readings

\begin{tabular}{|c|c|}
\hline SPECIMEN & RATE OF BURNING \\
\hline UNITS & $(\mathrm{mm} / \mathrm{min})$ \\
\hline A & 20.27 \\
\hline B & 19.45 \\
\hline
\end{tabular}

\section{RATE OF BURNING ( $\mathrm{mm} / \mathrm{min})$}

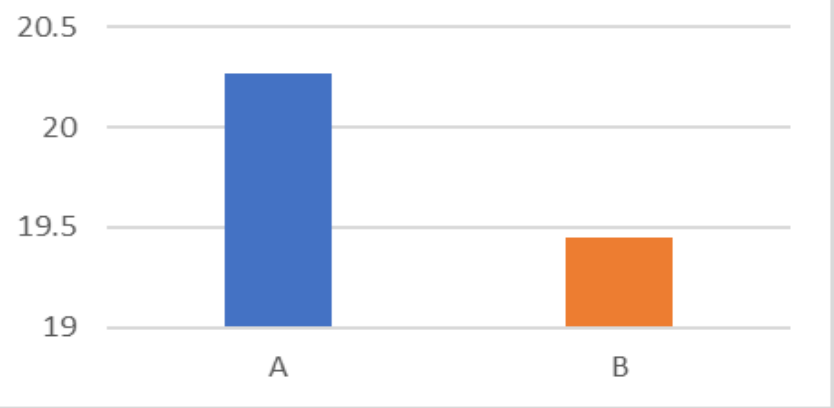

Fig. 15. Comparison of specimens based on Rate of burning.

Published By:

Blue Eyes Intelligence Engineering and Sciences Publication

(C) Copyright: All rights reserved.

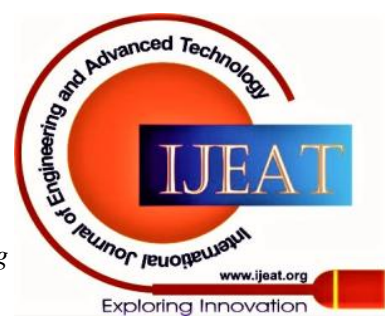




\section{SURFACE TOPOLOGY}

A scanning electron microscope (SEM) is a type of electron microscope that produces images of a sample by scanning the surface with a focused beam of electrons. The electrons interact with atoms in the sample, producing various signals that contain information about the surface topography and composition of the sample. SEM can achieve resolution better than 1 nanometre. Initially the sample which is to be scanned is Gold coated in an enclosed chamber for one minute prior to conducting SEM, this coating is done to improve electrical conductivity which eases the imaging process[12]. From Fig.16 we can see the scanned image of E-glass fiber at $100 \mu \mathrm{m}$ before impact and we could infer that molecules are brittle in nature and hence it is not much denser when compared with the Bamboo fibre before impact at $100 \mu \mathrm{m}$ as shown in Fig. 17. Due to this brittleness nature of E-glass It lacks certain mechanical properties when compared with a Bamboo Composite

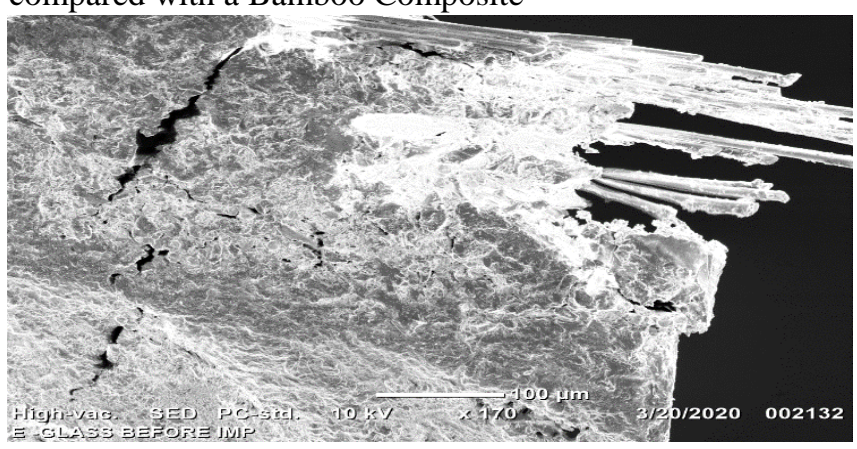

Fig. 16.SEM image of E-Glass composite before impact Fig.18 Shows the after-impact test conducted on the E-glass fibre sample at $50 \mu \mathrm{m}$. Due to the Brittleness of the E-glass Fibre the molecules of the E-glass Shattered completely showing the low integrity of the material, while on the other hand the Bamboo fibre shows little to no change in surface topology even after it is subjected to an impact test. Fig.19 shows the Bamboo Fabric after impact at $50 \mu \mathrm{m}$.

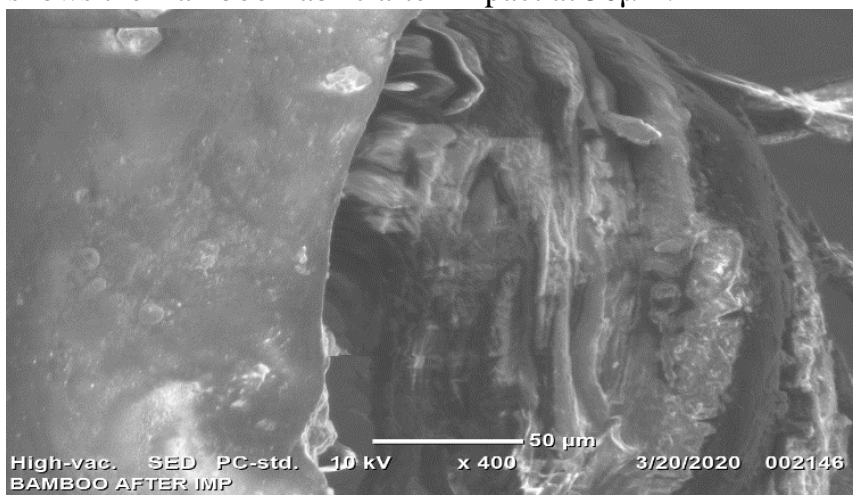

Fig. 17.SEM image of Bamboo composite before impact

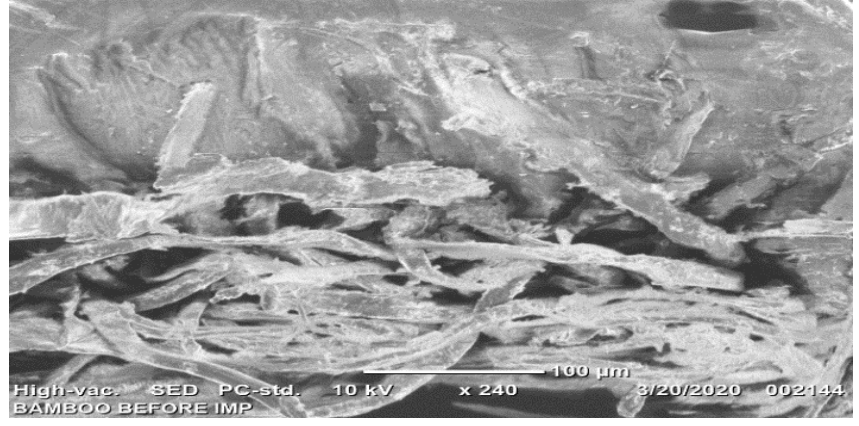

Fig. 18.SEM image of E-Glass composite after impact

Retrieval Number: 100.1/ijeat.A17131010120

DOI:10.35940/ijeat.A1713.1010120

Journal Website: www.ijeat.org

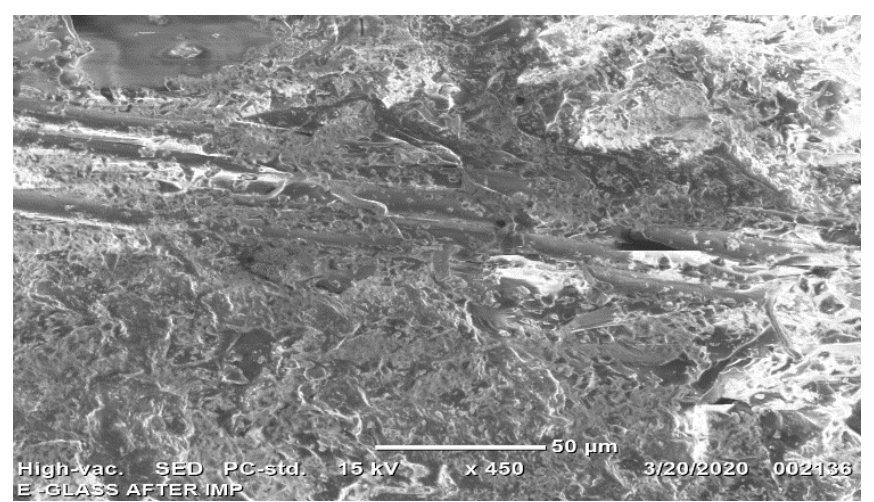

Fig. 19.SEM image of Bamboo composite after impact

\section{CONCLUSION}

In an era of volatile environment usage of natural fiber as reinforcement has been proven as environment friendly alternative to traditional synthetic fibers. Extensive study has been made to compare the mechanical strength of Bamboo Fiber and E-glass fiber reinforced composite, with an outcome proving the following Inference,

- Mechanical properties of Bamboo Fabric composite are almost at par with the E-glass fabric in every aspect, considering the environmental aspect it is wise to use natural based natural Bamboo fabric composite than the E-glass composite.

- Since both Bamboo fabric composite and E-glass composite has almost the same hardness level, Bamboo fabric composite can replace the E-glass composite in Hardness oriented applications.

- As the percentage of rate of water absorption of Bamboo Fabric composite is equivalent to that of the E-glass composite, Bamboo fabric composite can be used as a replacement in water related applications.

- Both the Bamboo Fabric composite and E-glass composite produces the same rate of burning, Bamboo fabric composite could also very well be used in the field of Thermal applications.

- SEM image shows that Bamboo fabric composite has better structural integrity compared to

E-Glass composite even after the impact is made.

- Further research on Bamboo fabric mat is recommended, tested with different filler material and resins in order to increase the mechanical property and structural integrity Bamboo fabric composite.

\section{REFERENCES}

1. A.K. Mohanty, A. Wibowo, M. Misra, L.T. Drzal, "Effect of process engineering on the performance of natural fibre reinforced cellulose acetate bio composites",

2. Ir. Eduardo Trujillo, Ir. Lina Osorio, Dr. Aart Van Vuure, Prof. Jan Ivens, Prof. Ignaas Verpoest "Bamboo (Guadua angustifolia) fibres for STRONG-light composite materials".

3. Kazuya Okubo, Toru Fujii, Yuzo Yamamoto "Development of Bamboo-based polymer composites and their mechanical properties".

4. Moe Yuzu Thwea Kin Liaob "Durability of Bamboo-glass fibre reinforced polymer matrix hybrid composites".

\section{Published By:}

Blue Eyes Intelligence Engineering

and Sciences Publication

(C) Copyright: All rights reserved.

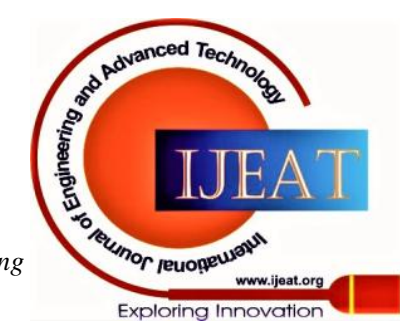


5. Mohd Yussni Hashim, Mohd Nazrul Roslan, Azriszul Mohd Amin, Ahmad Mujahid Ahmad Zaidi, Saparudin Ariffin "Mercerization Treatment Parameter Effect on Natural Fiber Reinforced Polymer Matrix Composite: A Brief Review".

6. Anuj Kumar A, Arun Gupta, K.V. Sharma, Mohammed Nasir, Tanveer Ahamed Khan "Influence of activated charcoal as filler on the properties of wood composites".

7. Toshihiko HOJO, Zhilan XU, Yuqiu YANG, Hiroyuki HAMADA "Tensile Properties of Bamboo, Jute and Kenaf Mat-Reinforced Composite".

8. C. Elanchezhian, B. Vijaya Ramnath, G. Ramakrishnan, M. Rajendrakumar, V. Naveenkumar, M. K. Saravanakumar. "Review on mechanical properties of natural fiber composites".

9. Sahas Bansal, M. Ramachandran "Comparative Analysis of Bamboo using Jute and Coir Fiber Reinforced Polymeric Composites".

10. Lawrence C Banka, T. Russell, Gentry Benjamin, P. Thompson Jeffrey, S Russell "A model specification for FRP composites for civil engineering structures".

11. Pei Beia, Chen Liweia, Lu Changa "An Experimental Study on the Burning Behavior of Fabric used Indoor".

12. Khan Z, Yousif BF, Islam MM "Fracture behavior of Bamboo fiber reinforced epoxy composites, Composites".

\section{AUTHORS PROFILE}

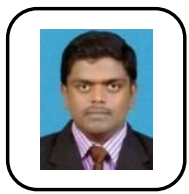

Mr. A. K. Arun Raja is working as an Assistant Professor in Mechanical Engineering Department in St. Joseph's Institute of Technology, OMR, Chennai, Tamil Nadu, India. He has a work experience of 7 years as assistant professor. He is currently pursuing his Ph.D. from Sathyabama University, OMR, Chennai, Tamil Nadu, India, in the topic "Bio Composites". He has done a total of 8 publications including Scopus and sci indexed journals. He has guided number of college students in completing their project on natural reinforced composites.

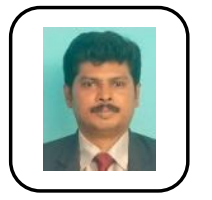

Dr. K. Arun Vasantha Geethan is working as a Professor and the Head Of the Department of Mechanical Engineering in St. Joseph's Institute of Technology, OMR, Chennai, Chennai, Tamil Nadu, India. He has a work experience of about 14 years in the field of teaching. He has done his Masters in Anna University, Chennai. He is also awarded with Doctor of Philosophy in "Reverse supply chain management" as area of research. He has a total of 26 publications including SCI and Scopus Indexed Journals.

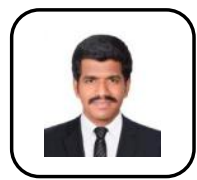

Mr. P Sabarish Kumar is working as an Assistan Professor in Mechanical Engineering Department in St. Joseph's Institute of Technology, OMR, Chennai-600 118. He has a work experience of 5 years in the field of teaching. He is currently pursuing his Ph.D. from SRM university, Kattankulathur, Chennai, Tamil Nadu, India with "Heat exchangers" as research area. He has done a total of 11 publications including Scopus indexed journals.

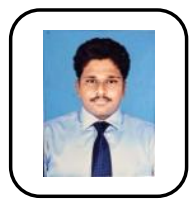

Mr. A Shagul Hameed is a Final year student pursuing his B. E. degree in mechanical engineering in St. Joseph's Institute of Technology, OMR, Chennai, Tamil Nadu, India. He is a member of SAE India Southern Section. He has done an academic project in "Design and Fabrication". He also completed a project for TVS Motors under the guidance of MSME-CDCE Automation. He also attended a lot of workshops and done In-plant trainings in notable companies such as Ashok Leyland and CDCE Automation.

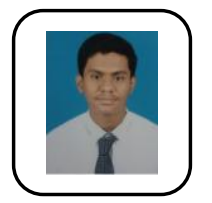

Mr. S. Vivekanandan is a final year student pursuing his B. E. degree in mechanical engineering in St. Joseph's Institute of Technology, OMR, Chennai, Tamil Nadu, India. He is a member of SAE India Southern Section. He has completed a project as intern trainee and has all done an academic project in "Design and Fabrication". He also completed a project for TVS Motors under the guidance of MSME-CDCE Automation. He has also attended a lot of workshops and in-plant of his department core industries.

Published By:

Blue Eyes Intelligence Engineering and Sciences Publication

(c) Copyright: All rights reserved.

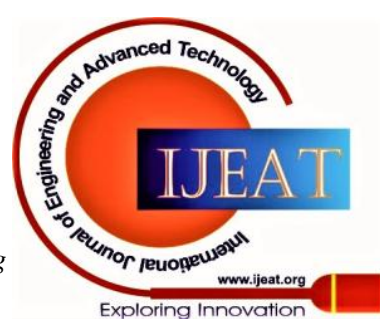

